\title{
COVID-19-Associated Deaths in San Francisco: the Important Role of Dementia and Atypical Presentations in Long-term Care Facilities
}

$\mathrm{J}$ Gen Intern Med 35(11):3413-5

DOI: $10.1007 / \mathrm{s} 11606-020-06206-1$

(c) Society of General Internal Medicine 2020

\section{BACKGROUND}

COVID-19 has caused significant mortality worldwide. ${ }^{1}$ Within the USA, marked geographic differences in incidence, hospitalization, and death have been reported. ${ }^{2}$ Better characterization of populations at increased risk for death from COVID-19 is needed, including from long-term care facilities (LTCF). We describe the demographic and clinical characteristics of the first 50 fatalities with COVID-19 in San Francisco.

\section{METHODS}

All San Francisco residents who die with laboratoryconfirmed COVID-19 infection are reported to the San Francisco Department of Public Health (SFDPH). We reviewed case report forms, medical records, and death certificate data for demographics, clinical presentation, and hospital course when applicable. Cause of death was not considered to be due to COVID-19 if not listed as the underlying cause of death on both the death certificate and medical record. These activities were public health surveillance, and not research; therefore, institutional review board review was not obtained.

\section{RESULTS}

From March 5 to July 14, 2020, 50 decedents with confirmed COVID-19 were reported. Of these, 46 had COVID-19 listed as the underlying cause of death and four were assessed as being unrelated to COVID-19; the non-COVID-19 causes of deaths were abdominal perforation, liver laceration, splenic laceration, and urosepsis.

The remaining 46 fatalities are described in Table 1. The average age was 81 years (range 30-100), and the most common race-ethnicity was Asian (49\%). The most common co-morbidities included dementia (46\%), diabetes mellitus $(43 \%)$, cardiac disease $(41 \%)$, and chronic lung disease

Received August 3, 2020

Accepted August 31, 2020

Published online September 15, 2020
(28\%). Common presenting symptoms included dyspnea $(48 \%)$, fever $\geq 100.0{ }^{\circ} \mathrm{F}(46 \%)$, cough $(30 \%)$, and altered mental status (25\%). Thirty-nine (89\%) were hospitalized, 24 $(59 \%)$ required intensive care, and $19(44 \%)$ were intubated. The mean time from symptom onset to death was 14.1 days (range $4 \mathrm{~h}-42$ days).

Twenty-one $(46 \%)$ decedents resided in a LTCF; most (84\%) were designated as DNR/DNI (do not resuscitate or intubate), comfort care, or hospice either preceding or at presentation. Ten (48\%) LTCF decedents presented without any fever, cough, and/or dyspnea; in six, altered mental status (e.g., confusion or lethargy) was the sole presenting symptom. When compared to community decedents, LTCF decedents were more likely to have a dementia diagnosis and to present with altered mental status and were less likely to present with cough, be hospitalized, receive intensive care or intubation, or be diagnosed with sepsis or acute renal failure.

\section{DISCUSSION}

Consistent with other reports, older adults in San Francisco remain the most likely to die due to COVID-19., 2 In San Francisco, as of July 30, 2020, persons $\geq$ 60 years comprise $14 \%$ of COVID-19 infections, yet $90 \%$ of deaths. ${ }^{3}$ Asians accounted for nearly half of deaths, though they comprise only $10.2 \%$ of COVID19 infections in San Francisco. ${ }^{3}$ In contrast, statewide and nationally, higher proportions of Latinos, Whites, and Blacks have died due to COVID-19. 1, 2, 4 This finding may be due to demographics specific to San Francisco; in 2019 , of persons $\geq 60$ years, $43 \%$ were Asian. $^{5}$

Most decedents had multiple co-morbidities reported by others, including diabetes and chronic cardiac and lung disease. ${ }^{1}$ However, we found dementia was the most frequent comorbidity, driven predominantly by LTCF residents who comprised nearly half of our decedents. Additionally, LTCF decedents were more likely to present with altered mental status; nearly half did not present with any typical COVID19 symptoms of fever, cough, or dyspnea. Presentation with altered mental status has also been reported in older COVID19 patients presenting to emergency medical services. ${ }^{6} \mathrm{Al}-$ though we found that LTCF cases were less likely to be hospitalized, receive aggressive medical interventions, or 
Table 1 COVID-19 Fatalities in San Francisco, March 5-July 14, 2020

\begin{tabular}{|c|c|c|c|c|}
\hline & Total & LTCF & Non-LTCF & $P$ value $^{\mathrm{a}}$ \\
\hline Number of fatalities, no. (\%) & 46 & $21(46)$ & $25(54)$ & \\
\hline Male, no. (\%) & $31 / 46(67)$ & $14 / 21(67)$ & $17 / 25(68)$ & NS \\
\hline Age, mean (range), years & $80.5(30-100)$ & $86.8(66-100)$ & $75.3(30-99)$ & 0.007 \\
\hline Race-ethnicity, no. (\%) & & & & 0.012 \\
\hline Asian & $22 / 45(49)$ & $14 / 21(67)$ & $8 / 24(34)$ & - \\
\hline White & $10 / 45(22)$ & $6 / 21(29)$ & $4 / 24(17)$ & - \\
\hline Hispanic & $9 / 45(20)$ & $0 / 21(0)$ & $9 / 24(38)$ & - \\
\hline Black & $4 / 45(9)$ & $1 / 21(5)$ & $3 / 24(13)$ & - \\
\hline \multicolumn{5}{|l|}{ Co-morbid conditions, no. (\%) } \\
\hline Dementia & $21 / 46(46)$ & $15 / 21(71)$ & $6 / 25(24)$ & 0.001 \\
\hline Diabetes mellitus & $20 / 46(43)$ & $11 / 21(52)$ & $9 / 25(36)$ & NS \\
\hline Chronic cardiac disease & $19 / 46(41)$ & $8 / 21(38)$ & $11 / 25(44)$ & NS \\
\hline Chronic lung disease & $13 / 46(28)$ & $7 / 21(34)$ & $6 / 25(24)$ & NS \\
\hline Immunocompromised & $6 / 46(13)$ & $3 / 21(14)$ & $3 / 25(12)$ & NS \\
\hline ESRD on HD & $5 / 46(11)$ & $3 / 21(14)$ & $2 / 25(8)$ & NS \\
\hline Obesity & $3 / 46(7)$ & $0 / 21(0)$ & $3 / 25(12)$ & NS \\
\hline Developmental delay & $3 / 46(7)$ & $0 / 21(0)$ & $3 / 25(12)$ & NS \\
\hline Average no. co-morbidities (range) & $4.4(1-11)$ & $5(1-11)$ & $3.7(1-10)$ & NS \\
\hline \multicolumn{5}{|l|}{ Symptoms ${ }^{b}$, no. (\%) } \\
\hline Dyspnea & $21 / 44(48)$ & $7 / 20(35)$ & $14 / 24(58)$ & NS \\
\hline Fever $>100.0^{\circ} \mathrm{F}$ & $20 / 44(46)$ & $6 / 20(30)$ & $14 / 24(58)$ & NS \\
\hline Cough & $13 / 44(30)$ & $2 / 20(10)$ & $11 / 24(46)$ & 0.010 \\
\hline Altered mental status & $11 / 44(25)$ & $9 / 20(45)$ & $2 / 24(8)$ & 0.006 \\
\hline Weakness & $9 / 44(21)$ & $3 / 20(15)$ & $6 / 24(25)$ & NS \\
\hline Anorexia & $7 / 44$ (16) & $2 / 20(10)$ & $5 / 24(21)$ & NS \\
\hline Gastrointestinal & $5 / 44(11)$ & $2 / 20(10)$ & $3 / 24(13)$ & NS \\
\hline Asymptomatic & $2 / 44(5)$ & $2 / 20(10)$ & $0 / 24(0)$ & NS \\
\hline Other & $2 / 44(5)$ & $0 / 20(0)$ & $2 / 24(8)$ & NS \\
\hline Hospitalized ${ }^{\mathrm{b}}$, no. $(\%)$ & $39 / 44(89)$ & $14 / 19(74)$ & $25 / 25(100)$ & 0.011 \\
\hline Intensive care ${ }^{b}$, no. $(\%)$ & $24 / 41(59)$ & $4 / 16(25)$ & $20 / 25(80)$ & 0.040 \\
\hline Intubated ${ }^{\mathrm{b}}$, no. $(\%)$ & $19 / 43(44)$ & $2 / 18(11)$ & $17 / 25(68)$ & $<0.001$ \\
\hline DNR/DNI/comfort care/hospice status ${ }^{\mathrm{b}}$, no. $(\%)$ & $27 / 43(63)$ & $16 / 19(84)$ & $7 / 25(28)$ & $<0.001$ \\
\hline \multicolumn{5}{|l|}{ Complications, no. $(\%)$} \\
\hline Pneumonia/ARDS & $44 / 46(96)$ & $19 / 21(90)$ & $25 / 25(100)$ & NS \\
\hline Sepsis & $21 / 46(46)$ & $5 / 21(24)$ & $16 / 25(64)$ & 0.006 \\
\hline Acute renal failure & $11 / 46(24)$ & $2 / 21(10)$ & $9 / 25(36)$ & 0.036 \\
\hline Secondary bacterial infection & $6 / 46(13)$ & $3 / 21(14)$ & $3 / 25$ (12) & NS \\
\hline Pulmonary emboli & $5 / 46(11)$ & $0 / 21(0)$ & $5 / 25(20)$ & NS \\
\hline Symptom onset to death ${ }^{\mathrm{b}}$, mean (range), days & $14.1(0-42)$ & $9.3(1-30)$ & $17.5(1-42)$ & 0.013 \\
\hline
\end{tabular}

$L T C F$, long-term care facility, NS, not significant; ESRD on HD, end-stage renal disease on hemodialysis; DNR/DNI, do not resuscitate/do not intubate, $A R D S$, acute respiratory distress syndrome

${ }^{a}$ The $\chi^{2}$ test was used for comparisons of categorical variables that had large values, and the Fisher exact test was used for comparisons of categorical variables with values $<5$. The T test was used for comparison of two independent means

${ }^{b}$ Includes patients with known information only

develop complications of sepsis or acute renal failure, they progressed more rapidly to death after symptom onset, likely reflecting the frail, debilitated state of many LTCF residents who are near end-of-life and have a DNR/DNI or comfort care status.

Our findings are a reminder that clinicians should remain vigilant for COVID-19 in older adults with dementia, who may present with atypical signs and symptoms and deteriorate quickly. Populations at risk for dying can vary greatly from region to region, and therefore public health policymakers should utilize local surveillance data to inform and target educational messages and prevention strategies.

Acknowledgments: Thank you to Amanda Reilly, MPH, University of California, Berkeley, for providing assistance with determining the elderly race-ethnicity demographics in San Francisco and to Howard Tokunaga, PhD, San Jose State University, for his review of our statistical methodology. We are also grateful to the SFDPH COVID-19 Skilled Nursing Facility (SNF) Outbreak Management Team, including Robin Allen-Contreras, Sabrina Alonso, Nicole Copeland, Adam Corona, George Lee, Kaylene Lemen, Talibah Miller, Melissa Ongpin,
Lisa Watson, Sheilah Zarate, and Angelo Clemenzi-Allen, for their 24/ 7 assistance with the care and management of COVID-19 positive HCWs and residents in San Francisco SNFs. We are indebted to Wayne Enanoria, PhD, Susan Philips, MD, MPH, and Tomas Aragon, $M D, D r P H$ for their support and leadership of the SFDPH COVID-19 response.

Janice K. Louie, $M D, M P H^{1,2}$

Hyman M. Scott, MD, MPH ${ }^{1,2}$

Wendy Lu, MPH ${ }^{1}$

Anna Chodos, $M D^{2}$

Amie DuBois, RN, PHN ${ }^{1}$

Natalya Sturtz, RN, PHN ${ }^{1}$

Juliet Stoltey, $M D, M P H^{1,2}$

${ }^{1}$ San Francisco Department of Public Health,

San Francisco, CA, USA

${ }^{2}$ University of California San Francisco, San Francisco, CA, USA

Corresponding Author: Janice K. Louie, MD, MPH; San Francisco Department of Public Health San Francisco, CA, USA (e-mail: Janice.louie@sfdph.org). 
Funding This work was financially supported by the San Francisco Department of Public Health.

\section{Compliance with Ethical Standards:}

Conflict of Interest: The authors declare that they do not have a conflict of interest.

\section{REFERENCES}

1. Wortham JM, Lee JT, Althomsons S, et al. Characteristics of Persons Who Died with COVID-19 - United States, February 12-May 18, 2020. MMWR Morb Mortal Wkly Rep 2020;69:923-929.

2. Hooper MW, Napoles AM, Perez-Stable EJ. COVID-19 and Racial/Ethnic Disparities. JAMA. 2020;323(24):2466-2467.
3. San Francisco Department of Public Health. COVID-19 Data and Reports. Available at URL: https://data.sfgov.org/stories/s/w6za-6st8. Last accessed August 2, 2020.

4. California Department of Public Health. COVID-19 Race and Ethnicity Data. Available at URL: https://www.cdph.ca.gov/Programs/CID/DCDC/ Pages/COVID-19/Race-Ethnicity.aspx. Last accessed August 2, 2020.

5. State of California Department of Finance Population Projections Baseline 2019. Available at URL: http://www.dof.ca.gov/forecasting/ demographics/projections/. Last accessed August 2, 2020.

6. Yang BY, Barnard LM, Emert JM, et al. Clinical Characteristics of Patients With Coronavirus Disease 2019 (COVID-19) Receiving Emergency Medical Services in King County, Washington JAMA Netw Open. 2020;3(7):e2014549

Publisher's Note: Springer Nature remains neutral with regard to jurisdictional claims in published maps and institutional affiliations. 